\title{
The Effect of Scaling and Root Planing on Total Antioxidant Status of Chronic Periodontitis Patients
}

\author{
Saufi Khairani ${ }^{1}$, Irma Ervina ${ }^{2 *}$, Pitu Wulandari ${ }^{2}$ \\ ${ }^{1}$ Periodontics Residency Program, Faculty of Dentistry, Universitas Sumatera Utara, Medan, \\ Indonesia \\ ${ }^{2}$ Department of Periodontics, Faculty of Dentistry, Universitas Sumatera Utara, Medan, \\ Indonesia \\ *Email: irma_ervina@rocketmail.com
}

\begin{abstract}
The objectives of this study was to analyse the effects of scaling and root planing on total antioxidant status in saliva and gingival crevicular fluid of patients with chronic periodontitis, at the Dental Hospital of Universitas Sumatera Utara, Indonesia. Methods: Saliva and gingival crevicular fluid samples were taken from all patients at their first visit to the clinic. Values for clinical parameters were recorded, and patients received scaling and root planing treatments. Two weeks later, saliva and gingival crevicular fluid samples were taken again, and clinical parameters were rechecked. The total antioxidant status of the saliva and gingival crevicular fluid samples were measured by spectrophotometry. Result: The total antioxidant status in the saliva of chronic periodontitis patients was higher after scaling and root planing, but the difference was not statically significant $(p>0.05)$. The total antioxidant status of gingival crevicular fluid was lower after treatment, but the difference was not statistically significant $(\mathrm{p}>0.05)$. The total antioxidant status in saliva was higher than that in gingival crevicular fluid, both before and after treatment, but the difference was not statistically significant $(p>0.05)$. There was no correlation $(p>0.05)$ between the total antioxidant status in saliva or gingival crevicular fluid and any clinical parameter, either before or after treatment. There was no effect of scaling and root planing on the total antioxidant status of saliva and gingival crevicular fluid in patients with chronic periodontitis.
\end{abstract}

Keywords: total antioxidant status, reactive oxygen species, scaling, root planning

\section{Introduction}

Chronic periodontitis is an inflammation of supporting tissues, characterised by gingival bleeding, periodontal pockets and loss of alveolar bone [1]. Polymorphonuclear leukocytes (PMNs) are the primary mediators of host responses to the proliferation of periodontal pathogenic microorganisms [2].

PMNs produce many reactive oxygen species, which can destroy periodontal tissues [2]. PMNs produce superoxide (O2) through respiratory burst during phagocytosis [3]. Reactive oxygen species have a function in normal metabolic reactions, but become toxic and destructive in high concentrations. This toxicity and can destroy gingival tissue, periodontal ligaments and alveolar bone [4]. Reactive oxygen species can cause lipid peroxidation, protein destruction and enzyme 
oxidation, and can stimulate monocytes and macrophages to release proinflammatory cytokines [5]. Oxidative stress increases in people with diabetes, because the products of reactive oxygen species are excessive, disturbing the balance of among oxidant and antioxidant cells [6]. Antioxidants can obstruct lipid, protein, carbohydrate and DNA oxidation [7]. The antioxidant capacity of periodontitis patients can be detected systemically and locally [8].

Saliva is a lubricant with antibacterial antioxidant components. Because saliva is a defence against free radicals, the prevention of oxidative stress begins with mastication and digestion, producing multiple reactions, including lipid peroxidation [3,9]. Both enzymatic and non-enzymatic antioxidants are found in saliva [10]. Enzymatic antioxidants (superoxide dismutase, glutathione peroxidase, peroxidase and catalase) neutralize free radicals directly, whereas non-enzymatic antioxidants (uric acid, albumin, glutathione, vitamins A and C, etc.) neutralize secondary oxidative products $[10,11]$.

Crevicular gingival fluid is secreted from gingiva at the gingival margin [4]. This fluid flows continuously through the epithelial tissue, and enters the gingival margin at a meagre flow rate $(0.24-1.56 \mu \mathrm{L} /$ minute in non-inflammatory conditions) [8]. It can be used as an indicator and sign of the destruction of bone and connective tissues [12]. Crevicular gingival fluid can be collected in various ways, including by paper strip [8], microcapillary pipette [12], the washing method [13] and paper point [14].

Comparison of antioxidant levels before and after scaling and root planing in healthy patients has shown that antioxidant levels increase after the treatments [10]. Non-surgical periodontal treatment procedures result in rehabilitation in clinical parameters (plaque index, gingival index, gingival bleeding, pocket depth and clinical loss of attachment) after two months [15]. The purpose of the current research was to analyse the influence of scaling and root planing on the total antioxidant status of chronic periodontitis patients, and to examine the total antioxidant status of saliva and the gingival crevicular fluid in patients with chronic periodontitis, before and after scaling and root planing, at Periodontia Installation of the Dental Hospital, University of Sumatera Utara.

\section{Materials and Methods}

This research used a pre- and post-test group design. Twenty subjects were chosen by purposive sampling, with inclusion criteria of 1) chronic periodontitis; 2) minimum of 20 remaining teeth; 3) loss of attachment $\geqslant 3 \mathrm{~mm}$; and 4) no periodontal treatments for the three last months. Patients who had a systemic history, were pregnant or lactating, were smokers, alcoholics or athletes, or who used mouthwash daily or consumed any vitamins, antibiotics or anti-inflammation drugs within the last month were excluded. The institutional ethical committee approved the research (No.64/KOMET/FK USU/2016), and all subjects gave informed consent. The researchers held positions at Periodontia Installation, Dental Hospital of the University of Sumatera Utara.

The materials utilized in this work were phosphate buffered saline (PBS) and QuantiChromTM Antioxidant Assay Kit (DTAC-100) reagents. The equipment used in this work included saliva containers, microcapillaries $(5 \mu \mathrm{L})$, Eppendorf 
cylinders, UNC-15 dental probes, spectrophotometers and microplates (Greiner Bio-One). Direct interviews were conducted to select the subjects. After the subjects were provided an explanation of the research, they were asked to fill out the informed consent. The data to be collected were the antioxidant statuses of saliva and crevicular gingival fluid of subjects with chronic periodontitis. The oral condition of each subject was determined at an initial examination. Gingival inflammation, pocket depth, loss of attachment, plaque index, calculus index, gingival bleeding index and the number of remaining teeth were measured to detect chronic periodontitis. A sample of saliva was collected in a polypropylene cylinder, using the spitting method. The subject was instructed to accumulate about $2 \mathrm{ml}$ of saliva at the bottom of the mouth, and to spit it into the cylinder. The sample was placed in a cooling box before being examined in the laboratory.

The crevicular gingival fluid was taken from around the teeth that had the deepest pockets. Before the fluid was collected, the teeth had to be cleaned of plaque and dried, then isolated with a cotton roll. The fluid was obtained using a $5 \mu \mathrm{L}$ microcapillary, gently applied to the gingival sulcus, using the intracrevicular superficial technique, for 5-20 minutes. The microcapillary was placed into an Eppendorf cylinder and kept in a cooling box before examination of the fluid. After both saliva and gingival fluid samples were taken, subjects received scaling and root planing treatments. The same sampling and treatment procedures were repeated after two weeks.

For analysis, $20 \mu \mathrm{L}$ of saliva were transferred to an Eppendorf cylinder, using a micropipette, then centrifuged at $4000 \mathrm{rpm}, 4 \mathrm{oC}$ for 30 seconds to remove debris. The saliva sample was mixed with the antioxidant assay kit reagents (A-Reagent, $100 \mu \mathrm{L}$; B-Reagent, $8 \mu \mathrm{L}$ ) and centrifuged to mix all solutions. After 10 minutes, 120 $\mu \mathrm{L}$ of the solution was transferred to a microplate well. Total antioxidant status was determined by computerised spectrophotometry.

Crevicular gingival fluid in the microcapillary was transferred to an Eppendorf cylinder, using a micropipette, and centrifuged for $4000 \mathrm{rpm}$ to collect the crevicular gingival fluid and to remove debris. For analysis, $1-5 \mu \mathrm{L}$ of crevicular gingival fluid were transferred to another Eppendorf cylinder, and PBS buffer solution was added to a total of $20 \mu \mathrm{L}$. The solution was centrifuged, then mixed with $100 \mu \mathrm{L}$ of Areagent and $8 \mu \mathrm{L}$ of B-reagent, and centrifuged once more. $120 \mu \mathrm{L}$ of that solution were transferred to a microplate well, and the total antioxidant status was determined by computerised spectrophotometry.

\section{Results}

A majority of the research subjects $(16 / 20,80 \%)$ were male. A total of $55 \%(11 / 20)$ of subjects were 18-35 years old. All subjects reported brushing their teeth 1-2 times a day, and no one used mouthwash after brushing. Of the 20 subjects, 17 $(85 \%)$ had never visited a dentist, $2(10 \%)$ visit the dentist once a year and $1(5 \%)$ visits the dentist once every 6 months. One subject uses dentures. Seventeen of the subjects $(85 \%)$ had moderate chronic periodontitis, and $3(15 \%)$ had severe chronic periodontitis.

The distribution of the data was measured using the Shapiro Wilk test for normality. The difference of total antioxidant status in saliva and crevicular gingival 
fluid of chronic periodontitis before and after scaling and root planing were compared using the t-test. The total antioxidant status in the saliva of chronic periodontitis patients before treatment was slightly higher than it was after treatment, but the difference was not statistically significant $(\mathrm{p}>0.05)$ (Table 1).

Table 1. Total antioxidant status in saliva of chronic periodontitis subjects before and after treatment

\begin{tabular}{|l|c|c|c|}
\hline & $\begin{array}{c}\text { Before Treatment } \\
(\text { Mean } \pm \text { SD) }\end{array}$ & $\begin{array}{c}\text { After Treatment } \\
(\text { Mean } \pm \text { SD) }\end{array}$ & $p$ \\
\hline $\begin{array}{l}\text { Total Antioxi- } \\
\text { dant Status }\end{array}$ & $225.44 \pm 141.51$ & $168.23 \pm 124.02$ & 0.151 \\
\hline
\end{tabular}

The total antioxidant status in crevicular gingival fluid of chronic periodontitis patients before treatment was lower than it was after treatment, but, according to the Wilcoxon signed-rank test, the difference was not statistically significant $(\mathrm{p}>0.05)$ (Table 2).

Table 2. Total antioxidant status of crevicular gingival fluid in chronic periodontitis subjects before and after treatment

\begin{tabular}{|l|c|c|c|}
\hline & $\begin{array}{c}\text { Before Treatment Median } \\
\text { (Min-Max) }\end{array}$ & $\begin{array}{c}\text { After Treatment Me- } \\
\text { dian (Min-Max) }\end{array}$ & $\boldsymbol{p}$ \\
\hline $\begin{array}{l}\text { Total Antioxidant } \\
\text { Status }\end{array}$ & $161(37-405)$ & $84.95(2.54-758)$ & 0.681 \\
\hline
\end{tabular}

Wilcoxon test, significant at $\mathrm{p}<0.05$

By using the Mann-Whitney U test, it was determined that the total antioxidant status in saliva was higher than that in crevicular gingival fluid, both before and after treatment, but the difference was not statistically significant $(\mathrm{p}>0.05)$ (Table 3).

Table 3. Comparison of total antioxidant status in saliva and crevicular gingival fluid of chronic periodontitis subjects before and after treatment

\begin{tabular}{|l|c|c|c|}
\hline $\begin{array}{c}\text { Total Antioxidant } \\
\text { Status }\end{array}$ & Saliva & $\begin{array}{c}\text { Crevicular Gingival } \\
\text { Fluid }\end{array}$ & $\boldsymbol{p}$ \\
\hline Before Treatment & $225.44 \pm 141.51$ & $167 \pm 133.01$ & 0.211 \\
\hline After Treatment & $168.23 \pm 124.02$ & $169 \pm 192.81$ & 0.398 \\
\hline
\end{tabular}

Mann-Whitney test, significant at $p<0.05$

Before treatment, there was a correlation between the total antioxidant status of saliva or crevicular gingival fluid and each clinical parameter. The total antioxidant status of saliva had positive correlations with plaque index, calculus index and bleeding index, but the correlations were not statistically significant $(p=0.20-$ 0.399). Bleeding index and loss of attachment showed minimal positive correlations with the antioxidant status of saliva $(\mathrm{p}=0.00-0.199)$, and the depth of pockets showed a minimal negative correlation $(\mathrm{p}=0.00-0.199)$. The correlations between antioxidant status of crevicular gingival fluid and plaque index, bleeding index, cal- 
culi index or loss of attachment were positive but small $(\mathrm{p}=0.20-0.399)$. The Pearson correlation coefficient showed that there was no significant correlation between total antioxidant status in crevicular gingival fluid and any clinical parameter of chronic periodontitis patients before treatment $(\mathrm{p}>0.05)$ (Table 4$)$.

Table 4. Correlation of total antioxidant status in saliva and crevicular gingival fluid with clinical parameters before treatment

\begin{tabular}{|l|c|c|c|c|}
\hline \multicolumn{1}{|c|}{ Parameter } & \multicolumn{3}{c|}{ Saliva } & \multicolumn{3}{c|}{ Crevicular Gingival Fluid } \\
\hline & $\mathbf{r}$ & $\boldsymbol{p}$ & $\mathbf{r}$ & $\boldsymbol{p}$ \\
\hline Plaque Index & 0.311 & 0.18 & 0.351 & 0.129 \\
\hline Bleeding Index & 0.157 & 0.50 & 0.229 & 0.331 \\
\hline Calculus Index & 0.262 & 0.26 & 0.388 & 0.091 \\
\hline Depth of Pocket & -0.12 & 0.61 & 0.063 & 0.793 \\
\hline Loss of Attachment & 0.07 & 0.75 & 0.314 & 0.17 \\
\hline
\end{tabular}

Pearson correlation test, 2-tailed, significant at $\mathrm{p}<0.05$

After treatment, the Pearson correlation coefficient showed that there was no significant correlation between total antioxidant status in saliva or crevicular gingival fluid with any clinical parameter in the subjects, except total antioxidant status of crevicular gingival fluid and plaque index (Table 5). The total antioxidant status of saliva had minimal positive correlations with plaque index, calculus index, depth of pocket and loss of attachment $(\mathrm{p}=0.00-0.199)$, and a modest negative correlation with loss of attachment $(\mathrm{p}=0.40-0.599)$.

Table 5. Correlation of total antioxidant status in saliva and crevicular gingival fluid with clinical parameters after treatment

\begin{tabular}{|l|c|c|c|c|}
\hline \multirow{2}{*}{ Parameter } & \multicolumn{4}{|c|}{ Saliva } \\
\cline { 2 - 5 } & $\mathbf{r}$ & $\boldsymbol{p}$ & $\mathbf{r}$ & $\boldsymbol{p}$ \\
\hline Plaque Index & -0.07 & 0.05 & 0.50 & $0.01 *$ \\
\hline Bleeding Index & 00.16 & 00.50 & 0,18 & 00.25 \\
\hline Calculus Index & -0.12 & 0.04 & 0,08 & 0.06 \\
\hline Depth of Pocket & -0.19 & 0.06 & 0.007 & 0.06 \\
\hline Loss of Attachment & -0.14 & 0.06 & -0.580 & 0.05 \\
\hline
\end{tabular}

\section{Discussion}

The results of this study are in agreement with those of Yang et al. [16], who studied 30 periodontitis patients, using saliva taken before and after scaling, to observe total antioxidant capacity and superoxide dismutase levels. They found that the total antioxidant capacity was lower after treatment.

Research by Kim et al. [17] demonstrated that total antioxidant status in the saliva of patients with severe chronic periodontitis is lower before scaling and root planing than it is after treatment. Superoxide dismutase activity of periodontitis patients was lower than that in the control group. Their research showed that the status of saliva may be used as a diagnostic tool for periodontal health.

Brock et al. studied the total antioxidant capacity of 20 non-smokers with locally 
chronic periodontitis (in the saliva and crevicular gingival fluid) and peripheral chronic periodontitis (in the plasma and serum). Their results showed that the antioxidant concentration of crevicular gingival fluid was lower in periodontitis subjects than in healthy patients. This contrasts with a study by Brock [18], where the total antioxidant status in the crevicular gingival fluid of periodontitis patients before treatment was lower than it was after treatment. The research by Scully and Langley, studying 129 patients with gingivitis and periodontitis, showed that the antioxidant level in saliva decreased and the oxidative destruction increased, compared to those in healthy patients This occurred because the antioxidant status in the saliva of chronic periodontitis patients adapted to the pathological conditions. When periodontitis is in the active phase, the immune system is activated, and reactive oxygen species are released because of an increase of PMNs. This results in the release of antioxidants in the body, accompanied by an increase of the antioxidant level in saliva. The total antioxidant status of severe chronic periodontitis patients does not change until three months after treatment, but the overall antioxidant status in healthy patients' increases after treatment until three months. This shows that non-surgical therapy does not alter total antioxidant status in severe chronic periodontitis patients $[17,19]$.

The current research showed that the total antioxidant status in saliva before scaling and root planing treatment was slightly higher than it was after treatment, and the total antioxidant status in crevicular gingival fluid before treatment was lower than it was after treatment, but neither of these differences was statistically significant $(\mathrm{p}>0.05)$. This means that treatment had no significant effect on total antioxidant status in saliva or crevicular gingival fluid of chronic periodontitis subjects. The concept that the total antioxidant status in healthy subjects is higher than it is in subjects with periodontitis was not supported by the data.

Factors other than those evaluated here, such as the presence of bacteria, nutrition, lifestyle, may influence the total antioxidant status in chronic periodontitis patients. Differences between results presented here and those of previous research may be due to the use of different methods and different inclusion and exclusion criteria. Inclusion in this study was not limited by age, possibly causing the data of total status antioxidant in chronic periodontitis subjects to be too diverse.

\section{Conclusion}

The total antioxidant status of saliva of chronic periodontitis patients before treatment was higher than it was after treatment, but the difference was not statistically significant $(\mathrm{p}>0.05)$. Conversely, the total antioxidant status of the crevicular gingival fluid of chronic periodontitis patients was lower before treatment than it was after treatment, but the difference is not statistically significant $(\mathrm{p}>0.05)$.

There was no significant correlation between any clinical parameter of chronic periodontitis patients and total antioxidant status of saliva. Total antioxidant status of crevicular gingival fluid was significantly correlated only with the plaque index after treatment. 


\section{References}

1. Azuma T, Yamane M, Ekuni D, Kawabata Y, Kataoka K, Kasuyama K, Maruyama T, Tomofuji T, Morita M. Drinking hydrogen-rich water has additive effects on non-surgical periodontal treatment of improving periodontitis: A pilot study. Antioxidants. 2015;4(3):513-22.

2. Liu Z, Liu Y, Song Y, Zhang X, Wang S, Wang Z. Systemic oxidative stress biomarkers in chronic periodontitis: a meta-analysis. Dis Markers. 2014;2014.

3. Jenifer HD, Bhola S, Kalburgi V, Warad S, Kokatnur VM. The influence of cigarette smoking on blood and salivary super oxide dismutase enzyme levels among smokers and nonsmokers - a cross sectional study. J Trad Complement Med. 2015;5(2):100-5.

4. Chakraborty S, Tewari S, Sharma RK, Narula SC, Ghalaut PS, Ghalaut V. Impact of iron deficiency anemia on chronic periodontitis and superoxide dismutase activity: a crosssectional study. J Periodont Implant Sci. 2014;44(2):57-64.

5. Azizi A, Sarlati F, Parchakani A, Alirezaei S. Evaluation of whole saliva antioxidant capacity in patients with periodontal diseases. Open J Stomatol. 2014;4(04):228.

6. Suarsana IN, Wresdiyati T, Suprayogi A. Respon stres oksidatif dan pemberian isoflavon terhadap aktivitas enzim superoksida dismutase dan peroksidasi lipid pada hati tikus. JITV. 2013;18(2):146-52.

7. Al-Rawi NH. Oxidative stress, antioxidant status and lipid profile in the saliva of type 2 diabetics. Diabet Vascul Dis Res. 2011;8(1):22-8.

8. Chapple IL, Brock G, Eftimiadi C, Matthews JB. Glutathione in gingival crevicular fluid and its relation to local antioxidant capacity in periodontal health and disease. Mol Pathol. 2002 Dec;55(6):367.

9. Battino M, Ferreiro MS, Gallardo I, Newman HN, Bullon P. The antioxidant capacity of saliva. J Clin Periodontol. 2002;29(3):189-94.

10. Novakovic N, Todorovic T, Rakic M, Milinkovic I, Dozic I, Jankovic S, Aleksic Z, Cakic S. Salivary antioxidants as periodontal biomarkers in evaluation of tissue status and treatment outcome. J Periodont Res. 2014;49(1):129-36.

11. Novaković N, Čakić S, Todorović T, Anđelski-Raičević B, Dožić I, Petrović V, Perunović N, Špadijer-Gostović S, Kadović-Sretenović J, Čolak E. Antioxidative status of saliva before and after non-surgical periodontal treatment. Srpski arhiv za celokupno lekarstvo. 2013;141(3-4):163-8.

12. Rahnama M, Czupkałło Ł, Kozicka-Czupkałło M, Łobacz M. Gingival crevicular fluidcomposition and clinical importance in gingivitis and periodontitis. Polish J Public Health. 2014 Apr 1;124(2):96-8.

13. Figueredo CM, Areas A, Miranda LA, Fischer RG, Gustafsson A. The short - term effectiveness of non - surgical treatment in reducing protease activity in gingival crevicular fluid from chronic periodontitis patients. J clin periodontol. 2004;31(8):615-9.

14. Ardiani DK, Dharmayanti AW, Pujiastuti P. Kadar Fosfor (P) dalam Cairan Sulkus Gingiva pada Penderita Penyakit Periodontal Phosphorus (P) Level of Gingival Crevicular Fluid of Peridontal Diseases. Insisiva Dent J. 2014;3(1):1-9.

15. Sukhtankar L, Kulloli A, Kathariya R, Shetty S. Effect of non-surgical periodontal therapy on superoxide dismutase levels in gingival tissues of chronic periodontitis patients: A clinical and spectophotometric analysis. Dis Markers. 2013;34(5):305-11.

16. Yang PS, Huang WC, Chen SY, Chen CH, Lee CY, Lin CT, Huang YK. Scaling-stimulated salivary antioxidant changes and oral-health behavior in an evaluation of periodontal treatment outcomes. The Scientific World Journal. 2014;2014.

17. Kim SC, Kim OS, Kim OJ, Kim YJ, Chung HJ. Antioxidant profile of whole saliva after scaling and root planing in periodontal disease. J Periodont Implant Sci. 2010;40(4):16471. 
18. Brock GR, Butterworth CJ, Matthews JB, Chapple IL. Local and systemic total antioxidant capacity in periodontitis and health. J Clin Periodontol. 2004;31(7):515-21.

19. Sculley DV, Langley-Evans SC. Periodontal disease is associated with lower antioxidant capacity in whole saliva and evidence of increased protein oxidation. Clin Sci. 2003;105(2):167-72. 